\title{
Enabling Effective E-Learning Creation on a Large Scale: Special-Purpose Authoring Tools
}

\author{
doi:10.3991/ijet.v4s3.1081 \\ D. Guralnick and C. Levy \\ Kaleidoscope Learning, New York, USA
}

\begin{abstract}
E-learning design and development today relies more on technological tools than ever before. In today's world, for budget and efficiency reasons, e-learning is often created by people without a technical background, using the authoring tools that are available to them. While this process is in some ways unavoidable, the result is that e-learning design is often dictated as much by the capabilities of existing authoring tools as by educational and design principles. In order to support the creation of more sophisticated, effective, educationally-sound e-learning on a large scale, I suggest an approach based on "special-purpose" authoring tools, designed around pedagogical models in a way that encourages good design and speeds up development. In this paper, I describe that approach and provide a brief example of the approach in use.
\end{abstract}

Index Terms - e-learning, authoring tools, learning by doing, simulations, scenarios

\section{INTRODUCTION}

E-learning design and development today in the business world relies more on technological tools than ever before. In today's world, for budget and efficiency reasons, a large percentage of e-learning is created by people without a technical background, using the platforms and authoring tools that are available to them. While this process is natural and in some ways unavoidable, the result is that e-learning design is often dictated as much by the capabilities of existing authoring tools as by educational goals and sound design principles. For example, in a 2008 survey by the E-Learning Guild (Wexler et al., 2008), corporate trainers were asked what they look for in an authoring tool to create self-paced e-learning. The most common responses focused on the following areas:

- Simplicity of updating of existing content;

- Short learning curve to learn how to use the tool;

- Support for particular output formats.

Not mentioned in these results is the ability of the tool to aid in the creation of effective e-learning. The prevailing theory, according to the E-Learning Guild survey and report, is that the quality of the product depends solely on the people creating it, not on the tool. Yet history and experience in several fields, as I will explain in detail later in this paper, suggest that the choice of authoring tool can indeed have a significant impact on the quality of an elearning product.

\section{POPULAR AUTHORING TOOLS IN TODAY's WORLD}

Most popular e-learning authoring tools (again focusing on self-paced e-learning) today fall into two categories: simpler tools, such as Lectora (www.lectora.com) or even general HTML tools such as Microsoft FrontPage and Adobe's Dreamweaver, that make it easy to build simple, page-turning e-learning; and course management systems such as Blackboard which are intended mainly to support classroom-based courses and have only limited support for the creation of self-paced e-learning. Building more sophisticated, educationally-sound e-learning with these simpler tools is difficult at best, and often impossible. These tools have their roles, but for the purposes of designing rich, effective, standalone e-learning, they suffer from the following problems:.

- They typically don't encourage good design (they do not contain a philosophy), or only encourage the design of simple, ineffective, page-turning courses;

- They can make it difficult for trainers to produce well-designed, effective e-learning - it often takes a lot of extra implementation effort to create something that is pedagogically effective using one of these tools, even when it is possible to do so.

According to a 2007 study by Bersin \& Associates, the most popular authoring tools among corporate trainers were the following: Authorware, DazzlerMax, Lectora, ReadyGo, Flash, Camtasia, and Captivate. Of those tools, only Authorware and Flash could be used to create rich elearning (with Captivate a bit closer than the rest), but programming in both Authorware and Flash is timeconsuming and difficult, generally considered something to be done by programmers or specialists, not by writers, subject matter experts, and trainers. Thus the majority of trainers use simple tools that create only simple, pageturning e-learning, perhaps with a quiz. Educational research (e.g., Brown, Collins, \& Duguid, 1989) has consistently shown that active, situated, authentic learning much more effective than passive learning-yet because of the tools available - for pragmatic reasons - the majority of trainer-created e-learning is of a style that is unlikely to be effective. Yet trainers generally have little choice: they are tasked with producing some kind of e-learning, quickly and inexpensively, and therefore must use the tools that they have available. If trainers only had the right tools available to them - tools the quality of corporate training worldwide could be greatly improved. 


\section{A (VERY) BRIEF HISTORY OF TOOLS}

For comparison purposes, it is worthwhile to consider the history of the use of tools in society in general. I'm viewing "tool" using the broad definition (one of several at www.freedictionary.com) of "[any] device that facilitates work." Tools were used as far back as the Stone Age (McClellan, 1999), as long as 2.5 million years ago. At that time, humans maintained a lifestyle which involved limited use of tools and there were few, if any, permanent settlements. The first major technologies, then, were tied to survival, hunting, and food preparation. Hammers were one of the earliest tools, and serve as a nice example for our purposes. Stones were used as simple hammers as far back as the Stone Age, and around the year 30,000 BC, hammers similar to today's form-stones attached to sticks by use of strips of leather-were in use.

Early, general-purpose hammers were gradually augmented with special-purpose tools, such as a miner's hammer, which has a point on one end and a traditional hammer head on the other, better for chipping and holding in a mine (source?). There are many special-purpose types of hammers today, such as a framing hammer, a geologist's hammer, and a rubber reflex hammer used by doctors. Some of these tools, such as the miner's hammer, are designed to perform their specific task in a better way than a simple hammer (a simple hammer is not especially useful for chipping, a pointed tool works faster and more accurately); others, such as the doctor's rubber-headed reflex hammer, are variations that perform tasks that an ordinary hammer would not be useful for at all (imagine a doctor hitting your knee with an ordinary hammer).

So based on the brief history of a hammer, we've seen that tools have an effect on what can be accomplished or produced, both in terms of how efficient it is to produce something and sometimes whether it is possible at all. The evolution of the hammer also demonstrates how specialpurpose tools can be designed to allow the completion of certain tasks, that general-purpose tools are not necessarily the most efficient or best way to do so.

\section{AnOther Perspective: Special-Purpose ToOls FOR E-LEARNING AUTHORING}

My perspective on authoring tools builds on the lessons learned from the evolution of the hammer: that generalpurpose tools need to be supplemented-and in many cases surpassed-by new, specialized authoring tools, which are designed specifically for particular pedagogical models and allow non-technical people to quickly and easily build rich, sophisticated e-learning. Specialized authoring tools under my definition have the following characteristics:

- They incorporate a philosophy-they don't build everything, but they build particular types of products easily;

- They can be very fast and easy to use, when designed well, and also inexpensive;

- They can work in place of or in addition to the general-purpose tools of today.

In the next section, I describe EncompassLite, a specialized authoring tool that contains templates based on elearning methodologies that have been shown to be successful. The first EncompassLite release contains a customer service learning-by-doing simulation template, based on a situated-learning approach (Brown, Collins \& Duguid, 1989; Guralnick, 2005) with built-in structures for coaching guidance and feedback, thus making it fast and easy for trainers to follow this successful model and also encouraging them to do so. Additional templates for EncompassLite will be suited for different content areas and, in some cases, will provide more general structures that are suited for numerous content areas. I believe that this special-purpose approach to tools has the potential to greatly increase e-learning effectiveness at a reasonable cost.

\section{ENCOMPASSLITE}

\section{A. Overview}

EncompassLite has been designed as a special-purpose tool to create certain types of effective e-learning. It contains a set of "rich templates" which allow corporate trainers to quickly and easily build self-paced, scenario-based e-learning using formats and methods-including coaching guidance and feedback styles - that have been used, reused, and tested and found to be successful over the years.

EncompassLite makes the creation of rich e-learning simple, and even more than that, it provides built-in structures and pedagogical models that support the creation of e-learning that is engaging and effective. The structures and models come from years of scenario-based e-learning developed by Kaleidoscope Learning in New York.

\section{B. Customer Service - The First EncompassLite Template}

\section{1) Background and Need}

The first release of EncompassLite focuses on customer service training, using a learn-by-doing simulation method. We chose this template as the first release partly because we have created a large number of similar customer service training programs in the past, and secondarily because there is seemingly always a high demand for good, customized customer service training, both for people who work in call centers and answer customers' calls, and for those who work at a customer service desk in a retail store. Customer service jobs are generally fairly high-turnover positions, requiring frequent hiring, and the are not high-paying and typically attract temporary, college-age worked. Yet the jobs require employees to be well-trained before they can begin work, and since customer service staff interacts directly with customers, these inexperienced, low-paid employees are very important to a customer's image of a company. Also, since employees are typically paid their regular wages during their training time, it is crucial from the company's perspective to train the employees in the shortest time possible-but do train them effectively, since the employees will be facing actual customers and must be prepared to do the job well. For these reasons, the idea of self-paced, online customer service training, able to train employees quickly and inexpensively, holds great appeal to many companies.

2) The Customer Service Training Learn-by-Doing Method

EncompassLite's customer service training templates follow a learn-by-doing model, in which the learner-a trainee-plays the role of a customer service representative and must handle "simulated" customer interactions. 
The simulated customers can appear in a combination of text, graphics, video, and audio, as desired by the course designer. The learner's task is to work through the issue that the customer presents as well as possible; the focus is primarily on customer service skills (e.g., how to be polite) and secondarily on company policy (e.g., what the company rule is for accepting a returned item without a receipt). On-screen, the learner must select from a set of options describing what to say to the customer. The learner can also ask for help from a coaching component at the bottom of the screen. A sample screen is shown in Figure 1.

After the learner selects an option, either the customer interaction continues, or the learner is interrupted by the teaching component with feedback as to why his choice was not a wise one. The number of paths, and the decisions regarding which options continue the story and which receive immediate teaching intervention are entirely up to the course designer. A sample screen with a teaching intervention is shown in Figure 2.

This learn-by-doing method has been used many times in similar forms, particularly by the team at Kaleidoscope Learning. It is based on educational theory (see Brown, Collins \& Duguid's 1989 work on situated cognition), and data from past projects shows that this method can indeed be effective in providing learners with engaging e-learning that can transfer well to use on the job (Guralnick, 2008).

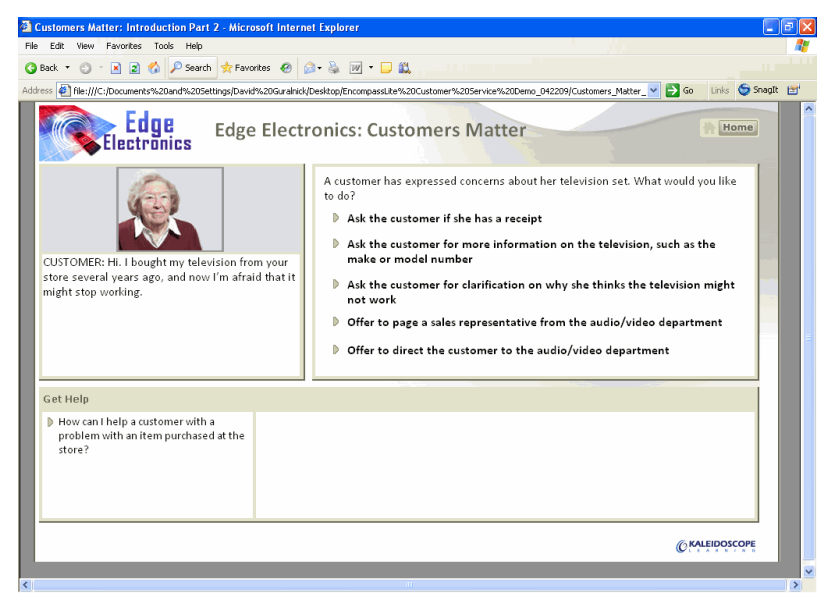

Figure 1. A customer service interaction screen.

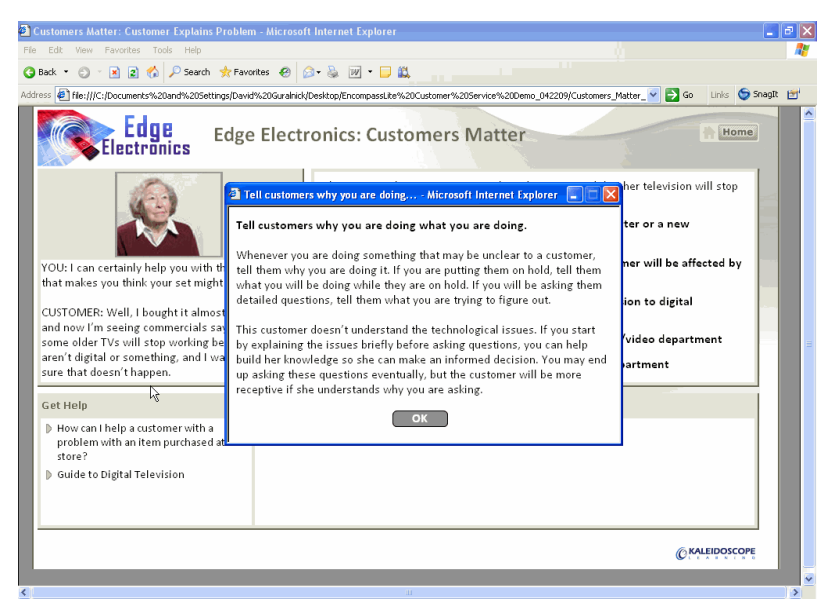

Figure 2. A customer service interaction screen showing feedback from the teaching component.

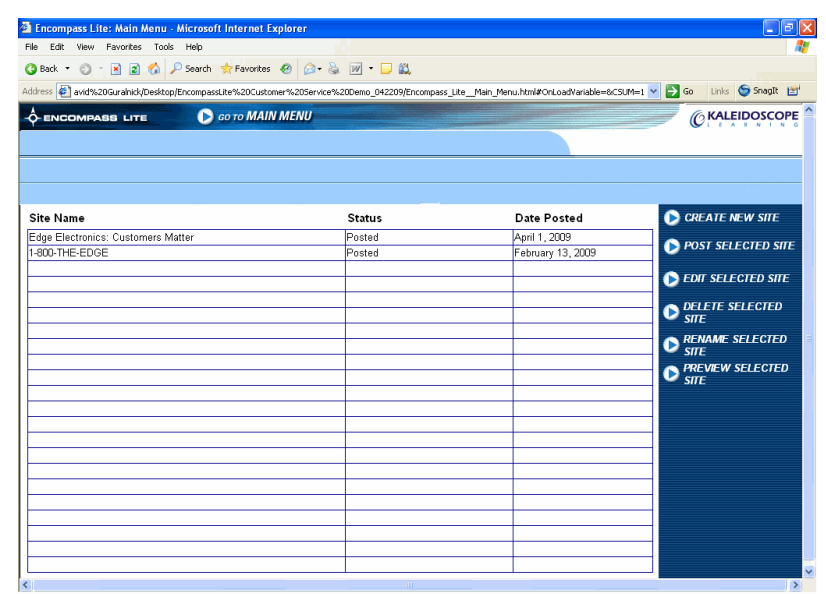

Figure 3. EncompassLite's main authoring menu screen showing all sites/courses.

The past success of this method, combined with the significant need for effective, customized customer service training by both large and small companies, made this an appropriate initial template set for EncompassLite.

\section{Authoring with EncompassLite}

Authoring with EncompassLite is generally done by corporate trainers. EncompassLite has been designed to make the authoring process simple and fast, and so that the authors do not need to have a technical background.

\section{1) Site Authoring}

Each course is considered a "site" in EncompassLite, though there is the option to use scenarios individually or in a just-in-time way. For customer service training, the concept of a course generally works well-learners must work through a set of scenarios (a series of different customers), which cover the key points that the learner needs to be able to master. A typical online course of this type runs for approximately eight scenarios, roughly an hour and a half of training, though each author's needs may be different. In EncompassLite, an author creates a new course, or site, very simply, as shown in Figure 3.

\section{2) Scenario Authoring}

Each scenario under the customer service model generally consists of an interaction with a single customer; the EncompassLite method and architecture is designed to handle scenarios of many types as additional templates are added to EncompassLite. Each site or course is made up of a series of scenarios, which learners generally take in a prescribed order. Learners can progress through a scenario along a series of paths, as defined by the author. A sample "scenario editor" screen is shown in Figure 4. Each scenario is made up of a series of pages - a "page" represents a single state in the scenario, with learner actions, feedback, and guidance. The customer service sample screen in Figure 1 was an example of a "page" in authoring tool terminology.

\section{3) Page Authoring}

Pages are, more than anything else, the heart of the EncompassLite scenario method, and where much of the richness of the interactions resides. Each page in a customer service scenario represents a "turn" in the scenario-where the learner must decide which action to take. In order to account for all possible actions that the learner may take, and follow for questions to be asked, the 
author must define the following core information for each page:

- The video, audio, graphic, text, or combination of media that appears in the "customer" area in the upper left-hand corner of the page

- The actions that the learner can take at this timee.g., "Tell the customer that she needs to buy a new television."

- The outcome of each action - either a new page that the action links to, continuing the scenario, or the teaching intervention that appears when the learner takes this action.

- The set of "help" questions that a learner can ask at this stage - e.g., "How do I know if a customer can afford a new TV?"

Specialized "page types" allow authors to construct pages of different formats - for example, a page with a "continue" button rather than actions to take, best used either to introduce a scene or to move the story along.

While pages do contain a lot of information, and it is imperative that authors think through their scenario design and content writing very carefully, implementation of pages is very simple and requires the author only to fill out a form. This method encourages the authors to think about guidance and feedback - they're included in the model - and also removes the burden of time-consuming, complex, and error-prone implementation that generalpurpose tools such as Authorware, FrontPage, and Flash involve. A sample page editor is shown in Figure 5.

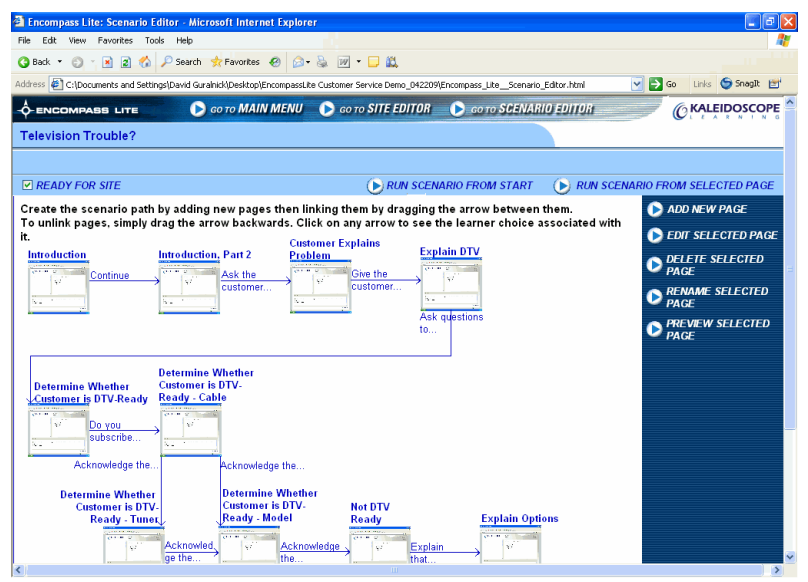

Figure 4. Authoring a scenario.

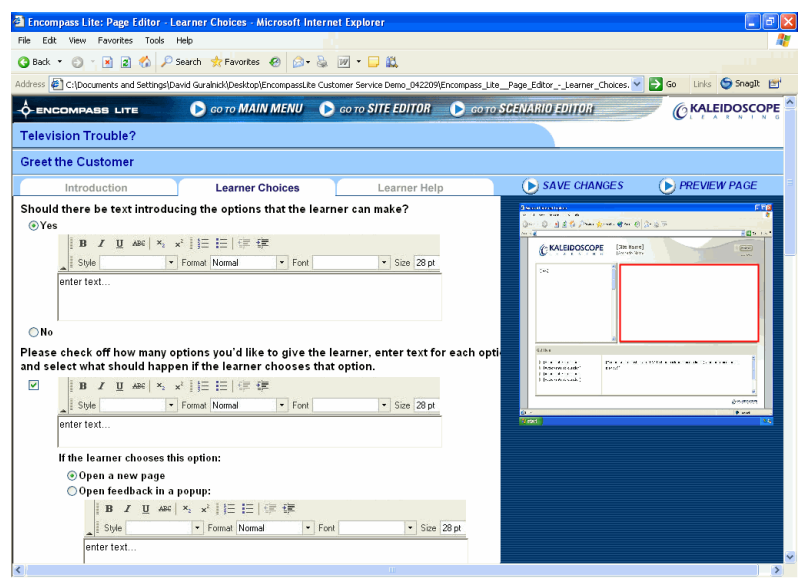

Figure 5. Authoring at the page level.

\section{4) Summary}

The "special-purpose" authoring tool approach used by EncompassLite has several advantages:

- Authors - generally corporate trainers - are able to create scenario-based training very quickly. Average implementation time is expected to be 15-20 minutes for a typical-length scenario

- The authoring tool's built-in structures ensure that a proven pedagogical model is used, thus increasing the chances that the resulting training scenarios will indeed be effective.

- The tool can be used by companies both big and small, for long-term and short-term needs. Positioned as a quick, inexpensive tool, EncompassLite can open up the possibility of scenario-based learning in situations where it has not been pragmatically feasible in the past.

- The EncompassLite technical architecture has been designed for easy expansion: the first release contains only the customer service template, but several other more-general templates are in process and will be possible to roll out quickly.

\section{CONCLUSION AND FUTURE WORK}

E-learning has been slow to reach its large-scale potential, especially in the corporate training world where large amounts of ineffective page-turning e-learning are still produced, mainly due to time and budget reasons. The advent of new, special-purpose authoring tools could address this issue, providing corporate trainers and others with easy-to-use that encourage and even enforce sound pedagogical design and the easy, inexpensive creation of sophisticated, effective e-learning such as learning simulations.

EncompassLite serves as an example of a specialpurpose authoring tool, and one that has several different future directions:

- The addition of more templates to support the creation of different scenario-based models - and eventually other models as well.

- Additional options within a template for further customization, particularly substantial customization of the screen look.

- Support for collaboration among authors, both for authoring and for sharing knowledge and ideas about scenario design.

- A "design assistance" component, which guides an author through the complete scenario design process, beginning with what specific points need to be taught.

We hope that EncompassLite can be the first of many tools of this type, so that trainers no longer follow the ancient axiom that "if all you have is a hammer, everything looks like a nail." E-learning has great unrealized potential, and special-purpose authoring tools can bring that potential into widespread use.

\section{REFERENCES}

[1] Brown, J. S., Collins, A., \& Duguid, P. (1989). Situated cognition and the culture of learning. Educational Researcher, 18 (pages 3242) 
[2] Guralnick, D. (2005). Creating Online Simulations to Teach Social Skills. European Conference on E-Learning, Amsterdam.

[3] Guralnick, D. (2008). Putting the Education into Educational Simulations: Pedagogical Structures, Guidance and Feedback. International Conference on Computer-Aided Learning, Villach, Austria.

[4] McClellan, James E. (1999). Science and Technology in World History: An Introduction. Baltimore, Maryland: Johns Hopkins Press.

[5] Wexler, S., Schlenker, B., Bruce, B., Clothier, P., Miller, D.A., \& and Nguyen, F. (2008). Authoring \& Development Tools. Santa Rosa, CA: The eLearning Guild

\section{AUTHORS}

David Guralnick (dguralnick@kaleidolearning.com) is with Kaleidoscope Learning, New York, NY 10010, USA.

Christine Levy (clevy@kaleidolearning.com) is also with Kaleidoscope Learning, New York, NY 10010, USA.

This article was modified from a presentation at the International Conference of Interactive Computer Aided Learning ICL2009, September 2009 in Villach, Austria. Submitted 17 October 2009. Published as resubmitted by the authors on 2 November 2009. 